\title{
Principal Component Analysis (PCA) and Construction of a SIMCA Classification Model to Monoterpenes and Analogs with Larvicidal Activity in Aedes aegypti
}

\author{
Carvalho, T. G. C.; Santos, I. M.; Bedor, C. N. G.; Alencar-Filho, E. B.*
}

Rev. Virtual Quim., 2019, 11 (2), 411-424. Data de publicação na Web: 21 de março de 2019

http://rvq.sbq.org.br

\section{Análise de Componentes Principais (PCA) e Construção de um Modelo de Classificação SIMCA para Monoterpenos e Análogos com Atividade Larvicida em Aedes aegypti}

Resumo: As arboviroses Dengue, Zika e Chicungunya são importantes problemas globais de saúde pública, que podem ser transmitidas, principalmente, durante o repasto sanguíneo do mosquito Aedes aegypti. A prevenção destas doenças é realizada comumente através do controle ambiental do inseto por métodos químicos, físicos ou biológicos, em seus estágios larval e/ou adulto. Produtos naturais têm sido estudados como alternativas químicas mais seguras e eficazes, empregando-se extratos, frações e compostos isolados. Baseados em um artigo de Santos e colaboradores, os quais relatam a atividade larvicida de monoterpenos e compostos análogos em Aedes aegypti, este trabalho apresenta uma forma não usual de seleção de variáveis, baseada no Agrupamento por Coeficientes de Variação (CCV), visando gerar um modelo de classificação através da técnica SIMCA, capaz de auxiliar na busca por compostos com maior potencial larvicida.

Palavras-chave: Monoterpenos; Aedes aegypti; arboviroses; atividade larvicida; algoritmo baseado em CCV; SIMCA.

\begin{abstract}
The arboviruses Dengue, Zika and Chicungunya are global public health problems that can be mainly transmitted by the bit of the Aedes aegypti mosquitoes. The prevention of these diseases involves the insect control, by chemical, physical or biological methods, considering both larval and adult stages. Natural products have been studied as more secure and effective chemical alternatives, through the use of extracts, fractions, and isolated compounds. Based on the previous paper of Santos and coworkers, which related the larvicidal activity of monoterpenes and analogs against Aedes aegypti, this work presents an unusual variable selection procedure, based on Clustering Coefficients of Variation (CCV) method, aiming to generate a classification model by SIMCA, capable of helping in the search of compounds with greater larvicidal potential.
\end{abstract}

Keywords: Monoterpenes; Aedes aegypti; arboviruses; larvicidal activity; CCV-based algorithm, SIMCA.

* Universidade Federal do Vale do São Francisco, Laboratório de Modelagem Molecular Aplicada a Farmácia (LAMMAF), Colegiado de Farmácia, CEP 56304-205, Petrolina-PE, Brazil.

Medilson.beserra@univasf.edu.br

DOI: $\underline{10.21577 / 1984-6835.20190031}$ 


\section{Principal Component Analysis (PCA) and Construction of a SIMCA Classification Model to Monoterpenes and Analogs with Larvicidal Activity in Aedes aegypti}

Thiego G. C. Carvalho, ${ }^{a}$ leda M. dos Santos, ${ }^{b}$ Cheila N. G. Bedor, ${ }^{\text {b }}$ Edilson B. de Alencar Filho ${ }^{\mathrm{a}, \mathrm{b}, \mathrm{c}, *}$

\footnotetext{
a Universidade Federal do Vale do São Francisco, Laboratório de Modelagem Molecular Aplicada a Farmácia (LAMMAF), Colegiado de Farmácia, CEP 56304-205, Petrolina-PE, Brazil.

b Universidade Federal do Vale do São Francisco, Programa de Pós-Graduação em Ciências da Saúde e Biológicas, CEP 56304-205, Petrolina-PE, Brazil.

' Universidade Federal do Vale do São Francisco, Programa de Pós-Graduação em Recursos Naturais do Semiárido, CEP 56304-205, Petrolina-PE, Brazil

* edilson.beserra@univasf.edu.br
}

Recebido em 6 de março de 2019. Aceito para publicação em 6 de março de 2019

\section{Introduction}

\section{Material and Methods}

2.1. Molecular structures and geometry optimization

\section{Results and Discussion}

\section{Conclusion}

\section{Introduction}

The viral infections called "Dengue", "Zika" and "Chicungunya" are important public health problems that affect mainly tropical countries, which are characterized by large differences in income distribution, as well as in sanitary and urban conditions. ${ }^{1}$ These viruses are transmitted to humans mainly by the bit of the females of Aedes aegypti mosquitoes, which develop their initial larval stages under relatively higher temperatures, using exposed vessels containing standing water. $^{2,3}$

The actions to combat these diseases are primarily focused on prevention, basically through the interruption of the mosquito life cycle and its dissemination by chemical, physical or biological methods, as well as their combinations. ${ }^{4}$ The use of chemicals is one of the most used, considering the practicality and effectiveness binomial. However, the inherent environmental and toxicity risks of approved substances, beyond of the possibility of the resistant phenomena, make this method complementary to the actions of surveillance and environmental management. ${ }^{4,5}$

In an attempt to circumvent this scenario, the use of natural products has emerged as a less harmful and promissory alternative within 
chemical methods, considering extracts, their fractions as well as isolated compounds. ${ }^{6}$ In this context, the literature reports experimental and chemoinformatic efforts in the search of molecules with potential activity against Aedes aegypti. ${ }^{7-11}$ Our research group has been working with a data set of 55 monoterpenes and analog compounds with larvicidal activity, early related by Scotti and coworkers ${ }^{9}$, providing QSAR models using classical and field (3D) descriptors ${ }^{10,11}$.

Thus, in continuity to the chemoinformatic studies and investigations, this work brings as contribution the proposition of a classification model based on Principal Component Analysis (PCA), known as SIMCA (Soft Independent Modelling by Class Analogy), evaluating new aspects of the structure-activity relationships as well providing another computational tool to reduce the time, cost and efforts to the rational molecular design, proposition and screening of new analogs with larvicidal potential.

\section{Material and Methods}

\subsection{Molecular structures and geometry optimization}

Molecular structures of 55 monoterpenes and analogs (Figure 1) were constructed using $\mathrm{ACD} /$ ChemSketch $^{12}$ free software and the inputs for geometry optimizations were edited on GaussView $6^{\circ} .{ }^{13}$ An initial optimization was computed by PM6 semiempirical Hamiltonian, with a further refinement by DFT-B3LYP/6-31G+(d) level of theory, with calculation of vibrational harmonic frequencies. The calculations were done by GAUSSIAN $09 \mathrm{~W}^{\circ}$ program $^{14}$ at CENAPAD-UFC (http://www.cenapad.ufc.br/) cluster environment.

Molecular descriptors were calculated using Dragon ${ }^{\circ}$ software $^{15}$, generating more than 5000 different variables, representing contributions of functional groups, as well as topological and geometrical properties. The $\mathrm{IC}_{50}$ larvicidal activity values on Aedes aegypti were obtained from the paper of Scotti and coworkers ${ }^{9}$, and transformed to the $-\log \left(\mathrm{IC}_{50}\right)$ $=\mathbf{p I C}_{\mathbf{5 0}}$. With this transformation, more active compounds assume higher values. As a preprocessing, descriptors with the low standard deviation (less than 0.1 ) and zero values were discarded.

The samples set (55 molecules) were classified on active (MA) or inactive (MI) group, with 30 and 25 compounds respectively. Hierarchical Cluster Analysis (HCA) and data set analysis was used on this step, and, basically, the compounds with $\mathbf{p I C _ { 5 0 }}$ values lower than 3.0 were considered "inactive".

Variable selection procedure was done using a method based on the "Clustering Coefficient of Variation" (CCV), related in 2014 by Fong ${ }^{16}$ and coworkers, where the CV (Coefficient of Variation) corresponds to the standard deviation divided by the mean, for each variable. However, the exact method used by us - the sequence of all steps for the variable selection - was not exactly found in the literature, to the best of our knowledge.

After that, selected descriptors were added into a matrix together with a priori variables, previously related by our research group in a QSAR purpose ${ }^{11}$, being the new matrix submitted to an initial exploratory Principal Component Analysis (PCA). Based on loading values, as well in the tendencies to active or inactive clusters on scores plot, the number of variables was reduced, and a final Soft Independent Modeling of Class Analogies (SIMCA) was constructed using the active set (MA). A test set was defined and composed by 7 frontier samples $(5 a, 26 a, 51 a, 53 a, 30 a, 42 a$, 48a), from the initial 30 MA set, plus the 25 considered inactive (MI). The SIMCA training set was composed by the remained 23 actives, corresponding to the samples from the core distribution, aiming to generate a final predictive model. All the statistical analyses were done by Microsoft Excel ${ }^{\circ}$ and Statistica ${ }^{\circ}$ packages. 


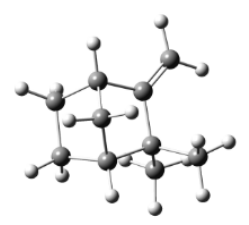

1

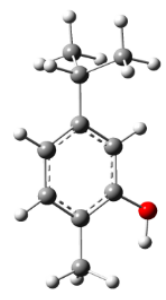

5

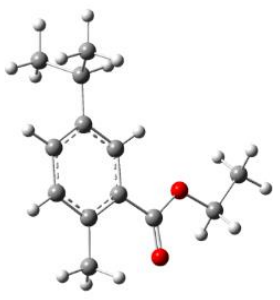

9

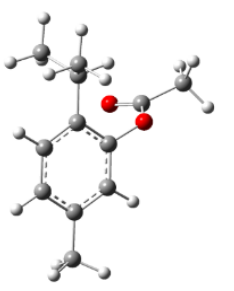

13

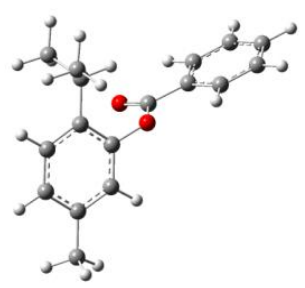

17

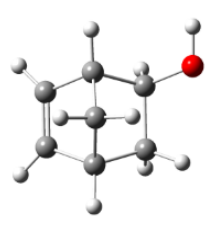

21

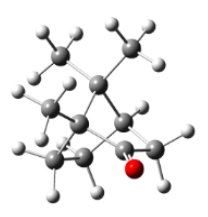

2

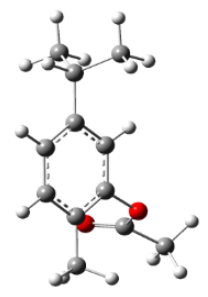

6

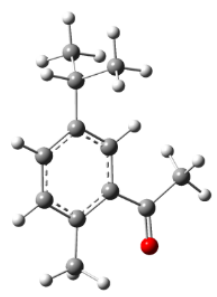

10

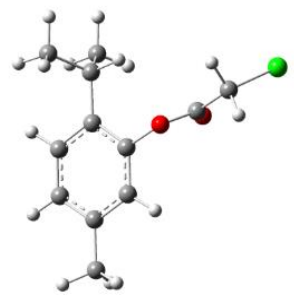

14

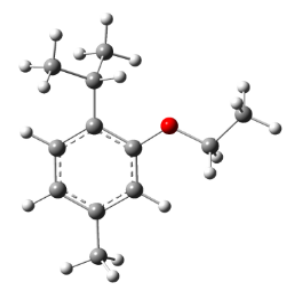

18

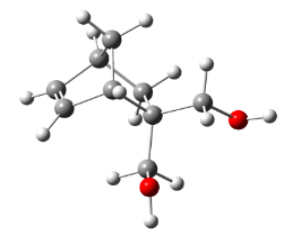

22

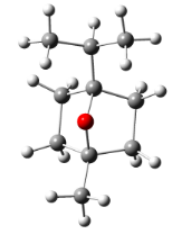

3

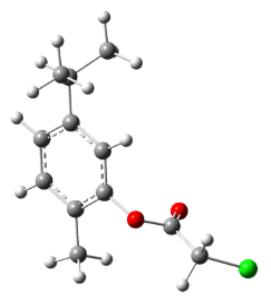

7

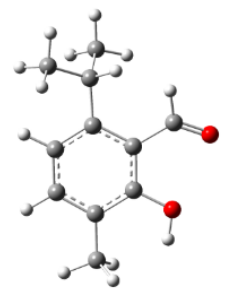

11

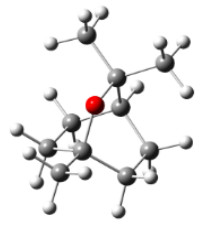

4

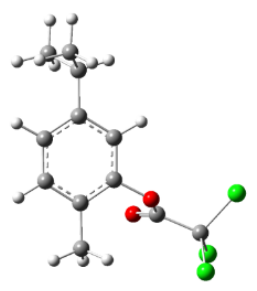

8

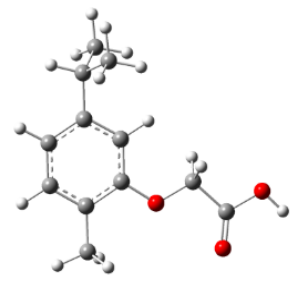

12

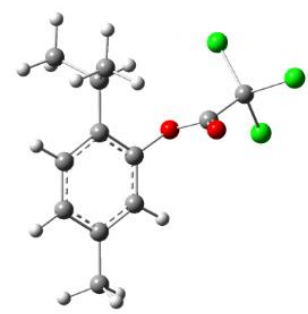

15

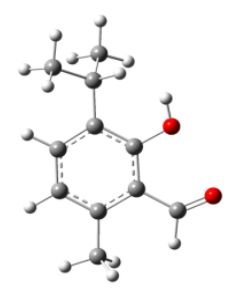

19

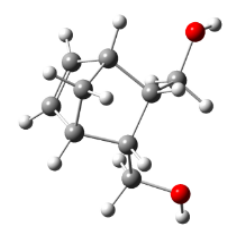

23

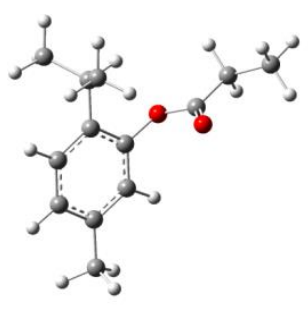

16

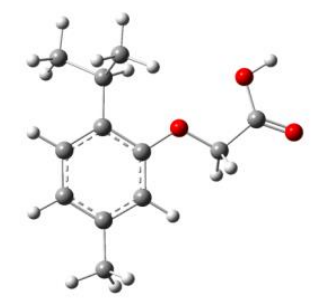

20

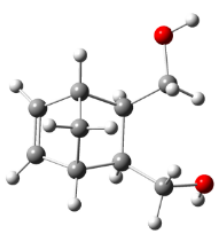

24 
Carvalho, T. G. C. et al.

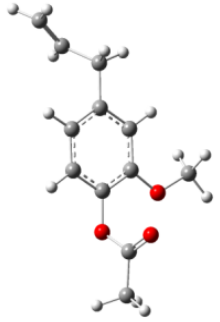

25

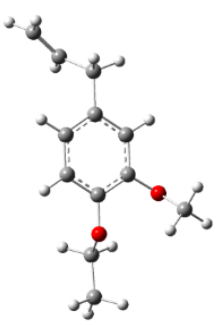

29

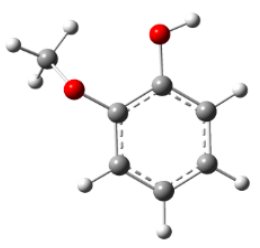

33

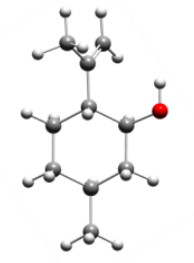

37

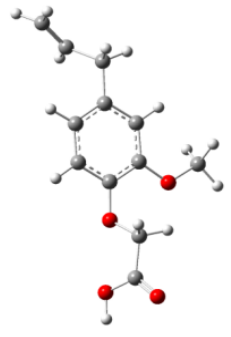

26

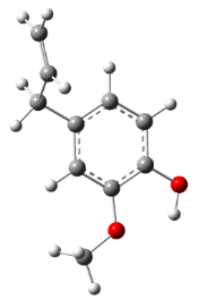

30

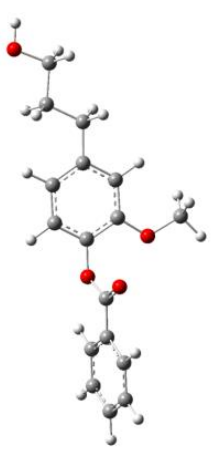

34

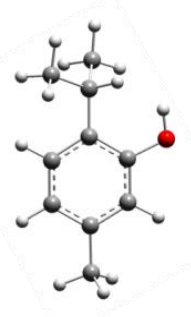

38

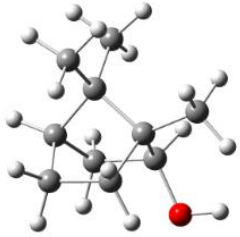

27

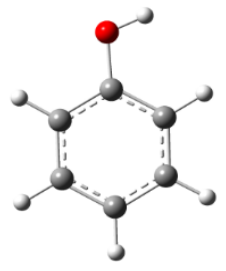

31

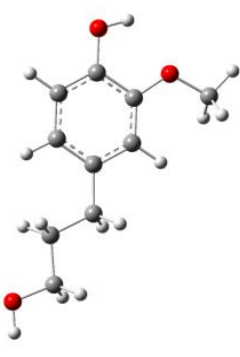

35

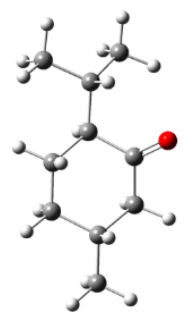

39
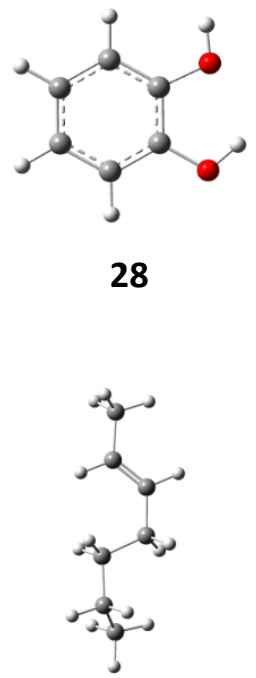

32
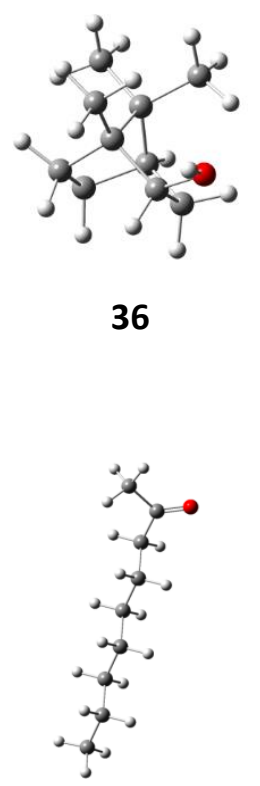

40 


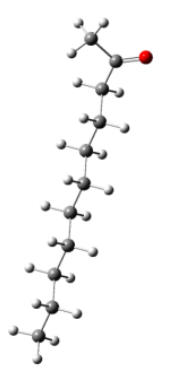

41

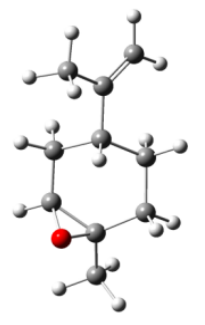

45

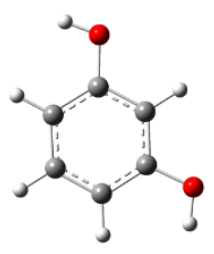

49

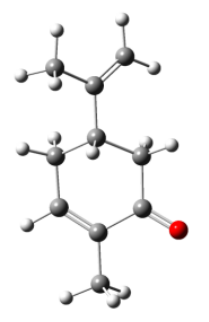

53

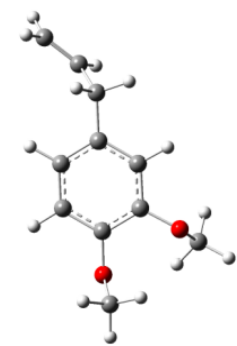

42

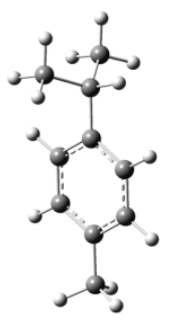

46

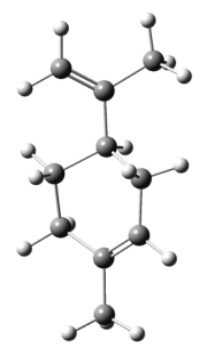

50

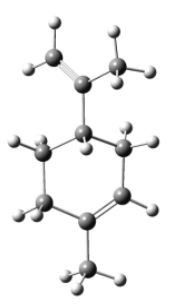

54

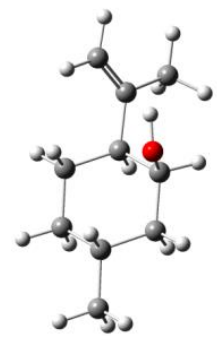

43

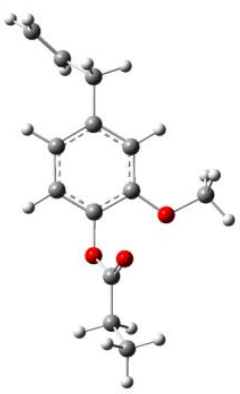

47

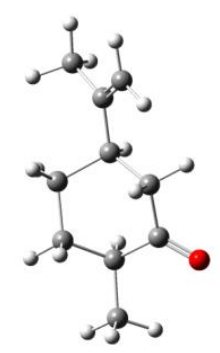

51

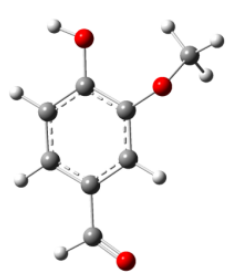

55

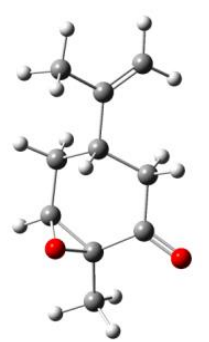

44

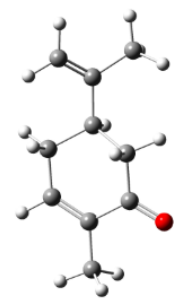

48

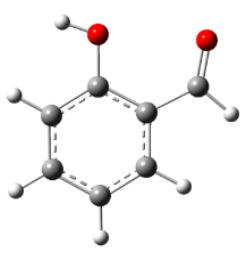

52

Figure 1. 3D optimized structures of monoterpenes and analogs (adapted from the other author's paper ${ }^{11}$ )

\section{Results and Discussion}

The relative structural simplicity of the monoterpenes and analogs, considering the little number of atoms and presence of rings (rigid profile), turns the geometry optimization to the minimal a less complex and reliable process, aiming the determination of the molecular descriptors by the Dragon ${ }^{\circ}$ software.

After the discard of descriptors with low standard deviation (less than 0.1 ) and zero values, the remaining 687 variables were submitted to a variable selection procedure, based on Clustering Coefficient of Variation 
(CCV) method. The CVV-based algorithm, described below, was not found in the literature (to the best of our knowledge), and was thought for us, in the way it was done. The Coefficient of Variation CV was calculated about all 687 descriptors, considering each group (MA and $\mathrm{MI}$ ) separately. For the next step, only variables with $1.0<\mathrm{CV}<2.5$ were considered, which would guarantee the homogeneity of the values of the variable for the respective set $(C V<2.0)$, without however having a null variation $(C V>1.0)$, with the risk of do not bring any information.

The idea presented by us, behind of the use of $\mathrm{CV}$, was that the first requirement for a variable to provide a good representation for a group is that it has a homogeneous distribution between the samples of this group. For this reason, the $\mathrm{CV}$ was chosen for being one way to express the data variability taking the influence of the numerical magnitude.

On the other hand, the values of a variable should be considerably different between different groups in an effective classification model, which is the second one required to improve the classification power. For fulfill this requirement, considering the little number of samples, the molecular descriptors as non-parametric data as well that the size of the groups were different, the method chosen was the classical Mann-Whitney test (MW). The logic of this test is the same as the $t$-test: a certain test statistic is calculated and the $p$ value is obtained from the sample distribution of this statistic, under the null hypothesis.

The difference of MW is that, instead of constructing this statistic with original data, they are previously converted into ordinations. The advantage is that the assumptions of normality and homogeneity of the variances are not necessary, allowing more general results. In their interpretation, the acceptance or not of the null hypothesis is made by the analysis of the $U$ number. This number is calculated as the sum of the orders of the values for the variable on each separated group, where a crescent sequential order $(10,2 \circ . . . n$ ) $)$ of the numerical values must be previously defined, using all absolute values of both groups in a unique column. The lower the $U$ value, the greater is the evidence that the populations are different. This is because $U$ is the sum of orders, so its value will be low if in category $A$ are the first values of the order (obviously in B will be the data of higher order). Then, the possible difference between the populations is evidenced. In addition, $p$-value can be analyzed, disregarding the null hypothesis of equality between the groups if $p<0.05$ (for $5 \%$ of significance).

In this way, seven variables were selected by the CVV-based algorithm (CV $<2.5$ and > 0.1 into groups and less $\mathrm{U}$ value after $\mathrm{MW}$ test), and were added into a matrix, plus five a priori descriptors, totalizing 12 variables (Table 1). Figure 2 shows the initial exploratory PCA for this data set about all 55 compounds, constructed with 3 PC's, where can be noted the influence of descriptors on clustering by the loadings plot. It can be noted that the scores plot already shows an initial separation between MA and MI clusters, but with only $66 \%$ of the total variance explained (PC1 $=33 \% ; P C 2=16 \%$ and $P C 3=13 \%$ ). After a loading based exhaustive search, the most representative variables that provided a good visual separation of MA and MI clusters were five, three from initial five a priori, and two from seven selected by the CCV-based algorithm: MLogP, R8u, nCt, Eta_sh_x and ChiA_Dz(Z).

The SIMCA procedure was made using as reference the thirty compounds of MA set, considering 23 for training and 7 for external test set (Table 2). The best classification model was composed of four PC's, with a total explained variance of $95 \%$, which represents an excellent exploitation of overall information. Using this model, their correct classificatory power was evaluated for all the 55 compounds ( 23 of training and 32 of the total test set). Table 2 shows the molecules and their classifications. As the model is based on active compounds, it is expected that the calculated descriptors for the inactive compounds will not be able to classify them into the model. On the other hand, the seven 
active compounds of the test set may be classified into the model.

In fact, considering the seven active samples tested, only 51a was incorrectly classified. However, observing the $\mathrm{pIC}_{50}$ value for 51a (3.11), we can conclude that this compound is in a frontier between active and inactive, which reinforces the good capability of the model that, in practice, was able to predict $100 \%$ of training and $86 \%$ of the test set (only one wrong). Considering the other 25 compounds of the test set, corresponding to the inactive group, only three were wrongly classified (20i, 38i, 40i), corresponding to a hit rate of $88 \%$ in not classifying then as actives (the expected).

Explaining these results, we can observe that the compound 20i has all the values of descriptors similar to active molecules (Table
$1)$, as for example, the compound 12a. However, it appears that the presence of the carboxylic acid group on the structure tends to impair the experimental value of $\mathrm{pIC}_{50}$, what is reinforced when we observed the activity value of 12 a (3.09), which represents on the lowest threshold of the active set. For the molecule 38i (2.59), the similar way can be explained in comparison with $5 a$ (3.47), where it appears that the hydroxyl group position significantly influences the larvicidal activity. Finally, compound $41 \mathrm{i}$ can be considered an anomalous compound together with 41 a, with which it bears structural and descriptors similarity. However, it is perceived that the size of the chain influences the potency, being the 41a (3.51) more active (although the value of $40 \mathrm{i}$ is not negligible (2.85), analyzing the cutoff used).

Table 1. $\mathrm{pIC}_{50}$ values and twelve variables used on modeling (a priori and selected by CCVbased algorithm)

\begin{tabular}{|c|c|c|c|c|c|c|c|c|c|c|c|c|c|}
\hline \multirow[t]{2}{*}{ Comp. } & \multirow[t]{2}{*}{$\mathrm{plC}_{50}$} & \multicolumn{5}{|c|}{ a priori descriptors } & \multicolumn{7}{|c|}{ Selected by CVV-based algorithm } \\
\hline & & MATS7e & VE1_SignA & $\mathrm{nCt}$ & MLogP & R8u & ChiA_Dz(Z) & Eta_sh_x & HOe & Eig02_AEA & RDF015s & R3v+ & R4e+ \\
\hline $1 \mathbf{i}$ & 2.79 & 0 & 0.202 & 2 & 3.374 & 0 & 0.058 & 0.1 & 2.733 & 2.427 & 17.027 & 0.032 & 0.06 \\
\hline $2 \mathbf{i}$ & 2.36 & 0 & 0.08 & 1 & 2.357 & 0 & 0.052 & 0.187 & 2.879 & 3.165 & 18.688 & 0.031 & 0.077 \\
\hline $3 \mathbf{i}$ & 2.31 & 0.215 & 0.039 & 2 & 2.357 & 0.33 & 0.049 & 0.187 & 2.745 & 3.1 & 24.008 & 0.024 & 0.057 \\
\hline $4 \mathbf{i}$ & 2.04 & 0 & 0.407 & 3 & 2.502 & 0 & 0.051 & 0.187 & 2.754 & 3.125 & 24.691 & 0.026 & 0.057 \\
\hline $5 a$ & 3.47 & 0.036 & 0.025 & 1 & 2.813 & 0.405 & 0.051 & 0 & 2.859 & 2.74 & 19.377 & 0.027 & 0.062 \\
\hline $6 a$ & 3.32 & -0.006 & 0.025 & 1 & 3.227 & 0.79 & 0.033 & 0 & 2.888 & 3.103 & 23.908 & 0.02 & 0.053 \\
\hline $7 a$ & 3.64 & -0.119 & 0.005 & 1 & 3.498 & 0.78 & 0.029 & 0 & 3.04 & 3.113 & 23.095 & 0.044 & 0.052 \\
\hline $8 a$ & 3.59 & -0.387 & 0.146 & 1 & 4.018 & 0.749 & 0.024 & 0.057 & 3.302 & 3.196 & 21.861 & 0.046 & 0.052 \\
\hline $9 a$ & 3.49 & -0.35 & 0.154 & 1 & 3.498 & 0.857 & 0.028 & 0 & 2.802 & 2.997 & 28.105 & 0.018 & 0.055 \\
\hline $10 a$ & 3.66 & -0.421 & 0.172 & 1 & 3.295 & 0.906 & 0.038 & 0 & 2.814 & 2.986 & 23.77 & 0.022 & 0.056 \\
\hline $11 a$ & 3.43 & 0.103 & 0.079 & 1 & 2.913 & 0.406 & 0.041 & 0 & 2.984 & 2.74 & 22.207 & 0.025 & 0.091 \\
\hline $12 a$ & 3.09 & -0.214 & 0.098 & 1 & 2.391 & 0.971 & 0.028 & 0 & 2.974 & 3.168 & 24.594 & 0.019 & 0.057 \\
\hline $13 a$ & 3.32 & -0.338 & 0.304 & 1 & 3.227 & 1.096 & 0.034 & 0 & 2.888 & 3.174 & 23.973 & 0.018 & 0.051 \\
\hline $14 a$ & 3.66 & -0.338 & 0.279 & 1 & 3.498 & 1.097 & 0.03 & 0 & 3.039 & 3.189 & 23.096 & 0.043 & 0.05 \\
\hline $15 a$ & 3.85 & -0.464 & 0.096 & 1 & 4.018 & 1.109 & 0.024 & 0.057 & 3.303 & 3.267 & 21.845 & 0.046 & 0.049 \\
\hline $16 a$ & 3.49 & -0.296 & 0.279 & 1 & 3.498 & 1.183 & 0.029 & 0 & 2.832 & 3.182 & 25.838 & 0.022 & 0.048 \\
\hline $17 a$ & 3.46 & -0.326 & 0.239 & 1 & 4.531 & 0.976 & 0.019 & 0 & 2.829 & 3.184 & 31.411 & 0.03 & 0.049 \\
\hline $18 a$ & 3.16 & 0.025 & 0.245 & 1 & 3.386 & 1.084 & 0.038 & 0 & 2.747 & 2.501 & 24.713 & 0.018 & 0.052 \\
\hline $19 a$ & 3.72 & -0.321 & 0.196 & 1 & 2.913 & 0.402 & 0.04 & 0 & 2.987 & 2.896 & 22.183 & 0.031 & 0.091 \\
\hline $20 \mathrm{i}$ & 2.65 & 0.008 & 0.184 & 1 & 2.391 & 0.923 & 0.028 & 0 & 2.973 & 3.249 & 24.34 & 0.018 & 0.056 \\
\hline $21 i$ & 2.16 & 0 & 0.147 & 2 & 1.403 & 0 & 0.085 & 0 & 2.865 & 2.245 & 17.497 & 0.033 & 0.085 \\
\hline $22 \mathbf{i}$ & 2.29 & 0.257 & 0.159 & 2 & 1.173 & 0 & 0.047 & 0.097 & 2.952 & 2.55 & 27.039 & 0.024 & 0.065 \\
\hline
\end{tabular}


Carvalho, T. G. C. et al.

\begin{tabular}{|c|c|c|c|c|c|c|c|c|c|c|c|c|c|}
\hline $23 i$ & 2.05 & 0.257 & 0 & 4 & 1.173 & 0 & 0.046 & 0 & 2.976 & 2.271 & 27.3 & 0.027 & 0.059 \\
\hline $24 i$ & 2.33 & 0.257 & 0 & 4 & 1.173 & 0 & 0.046 & 0 & 2.979 & 2.271 & 26.783 & 0.025 & 0.06 \\
\hline $25 a$ & 3.28 & -0.09 & 0.009 & 0 & 2.573 & 0.619 & 0.029 & 0 & 3.012 & 3.128 & 24.125 & 0.015 & 0.065 \\
\hline $26 a$ & 3.04 & -0.12 & 0.117 & 0 & 1.765 & 0.589 & 0.025 & 0 & 3.095 & 3.203 & 25.646 & 0.017 & 0.062 \\
\hline $27 i$ & 2.4 & 0 & 0.08 & 1 & 2.502 & 0 & 0.051 & 0.187 & 2.827 & 2.543 & 22.477 & 0.026 & 0.058 \\
\hline $28 i$ & 2.66 & 0 & 0 & 0 & 0.893 & 0 & 0.104 & 0 & 2.098 & 1.729 & 11.594 & 0.03 & 0.101 \\
\hline $29 a$ & 3.4 & 0.001 & 0.061 & 0 & 2.683 & 0.605 & 0.032 & 0 & 2.838 & 2.661 & 27.265 & 0.021 & 0.044 \\
\hline $30 a$ & 3.35 & -0.054 & 0.046 & 0 & 2.11 & 0.304 & 0.043 & 0 & 2.912 & 2.619 & 19.886 & 0.023 & 0.079 \\
\hline $31 i$ & 2.69 & 0 & 0.18 & 0 & 1.506 & 0 & 0.128 & 0 & 1.981 & 1.521 & 9.911 & 0.028 & 0.085 \\
\hline $32 a$ & 3.39 & -0.1 & 0.099 & 0 & 2.812 & 0.237 & 0.075 & 0 & 2.71 & 1.407 & 13.878 & 0.02 & 0.079 \\
\hline $33 i$ & 2.84 & 0.341 & 0.074 & 0 & 1.246 & 0 & 0.082 & 0 & 3.06 & 1.983 & 15.395 & 0.035 & 0.085 \\
\hline $34 a$ & 3.28 & -0.043 & 0.004 & 0 & 3.155 & 0.669 & 0.015 & 0 & 2.969 & 3.133 & 37.886 & 0.033 & 0.067 \\
\hline $35 i$ & 2.05 & 0.134 & 0.027 & 0 & 1.365 & 0.398 & 0.034 & 0 & 2.96 & 2.557 & 26.236 & 0.022 & 0.064 \\
\hline $36 i$ & 2.41 & 0 & 0.08 & 1 & 2.502 & 0 & 0.051 & 0.187 & 2.824 & 2.543 & 22.478 & 0.026 & 0.054 \\
\hline $37 i$ & 2.71 & -0.043 & 0.283 & 2 & 2.357 & 0.29 & 0.042 & 0 & 2.845 & 2.417 & 23.41 & 0.02 & 0.055 \\
\hline $38 i$ & 2.59 & -0.052 & 0.283 & 1 & 2.813 & 0.427 & 0.052 & 0 & 2.861 & 2.485 & 19.426 & 0.021 & 0.063 \\
\hline $39 i$ & 2.48 & 0.001 & 0.283 & 3 & 2.357 & 0.331 & 0.042 & 0 & 2.866 & 2.414 & 19.583 & 0.019 & 0.075 \\
\hline $40 i$ & 2.85 & -0.032 & 0.256 & 0 & 3.358 & 0.375 & 0.035 & 0 & 2.893 & 1.829 & 18.157 & 0.014 & 0.068 \\
\hline $41 a$ & 3.51 & -0.015 & 0.228 & 0 & 3.953 & 0.456 & 0.024 & 0 & 2.862 & 1.892 & 22.14 & 0.013 & 0.058 \\
\hline $42 a$ & 3.24 & 0.003 & 0.1 & 0 & 2.402 & 0.392 & 0.038 & 0 & 2.865 & 2.65 & 25.104 & 0.023 & 0.055 \\
\hline $43 i$ & 2.44 & -0.043 & 0.283 & 2 & 2.357 & 0.282 & 0.042 & 0 & 2.845 & 2.417 & 23.338 & 0.022 & 0.053 \\
\hline $44 i$ & 2.88 & -0.032 & 0.054 & 2 & 1.369 & 0.315 & 0.038 & 0.088 & 2.984 & 3.142 & 26.261 & 0.031 & 0.076 \\
\hline $45 i$ & 2.47 & -0.146 & 0.185 & 2 & 2.357 & 0.305 & 0.042 & 0.094 & 2.821 & 3.022 & 25.561 & 0.022 & 0.055 \\
\hline $46 a$ & 3.42 & -0.657 & 0.167 & 1 & 3.562 & 0.428 & 0.058 & 0 & 2.731 & 2.473 & 17.809 & 0.024 & 0.057 \\
\hline $47 a$ & 3.55 & -0.164 & 0.011 & 0 & 2.845 & 0.667 & 0.025 & 0 & 2.92 & 3.135 & 26.043 & 0.026 & 0.063 \\
\hline $48 a$ & 3 & -0.13 & 0.025 & 1 & 2.153 & 0.335 & 0.045 & 0 & 2.875 & 3 & 20.967 & 0.032 & 0.078 \\
\hline $49 i$ & 2.28 & 0 & 0.31 & 0 & 0.893 & 0 & 0.102 & 0 & 2.135 & 2.232 & 11.215 & 0.026 & 0.077 \\
\hline $50 a$ & 3.7 & -1 & 0.167 & 1 & 3.267 & 0.321 & 0.05 & 0 & 2.725 & 2.71 & 20.13 & 0.022 & 0.059 \\
\hline $51 a$ & 3.11 & -0.027 & 0.025 & 2 & 2.25 & 0.301 & 0.042 & 0 & 2.874 & 2.997 & 19.208 & 0.03 & 0.078 \\
\hline $52 i$ & 2.95 & 0 & 0.074 & 0 & 1.667 & 0 & 0.081 & 0 & 2.143 & 2.531 & 12.439 & 0.032 & 0.112 \\
\hline $53 a$ & 3.08 & -0.13 & 0.025 & 1 & 2.153 & 0.334 & 0.045 & 0 & 2.882 & 3 & 20.973 & 0.032 & 0.084 \\
\hline $54 a$ & 3.64 & -1 & 0.167 & 1 & 3.267 & 0.321 & 0.05 & 0 & 2.725 & 2.71 & 20.13 & 0.022 & 0.059 \\
\hline $55 i$ & 2.47 & -0.266 & 0.01 & 0 & 0.922 & 0 & 0.056 & 0 & 3.237 & 2.893 & 17.889 & 0.033 & 0.09 \\
\hline
\end{tabular}




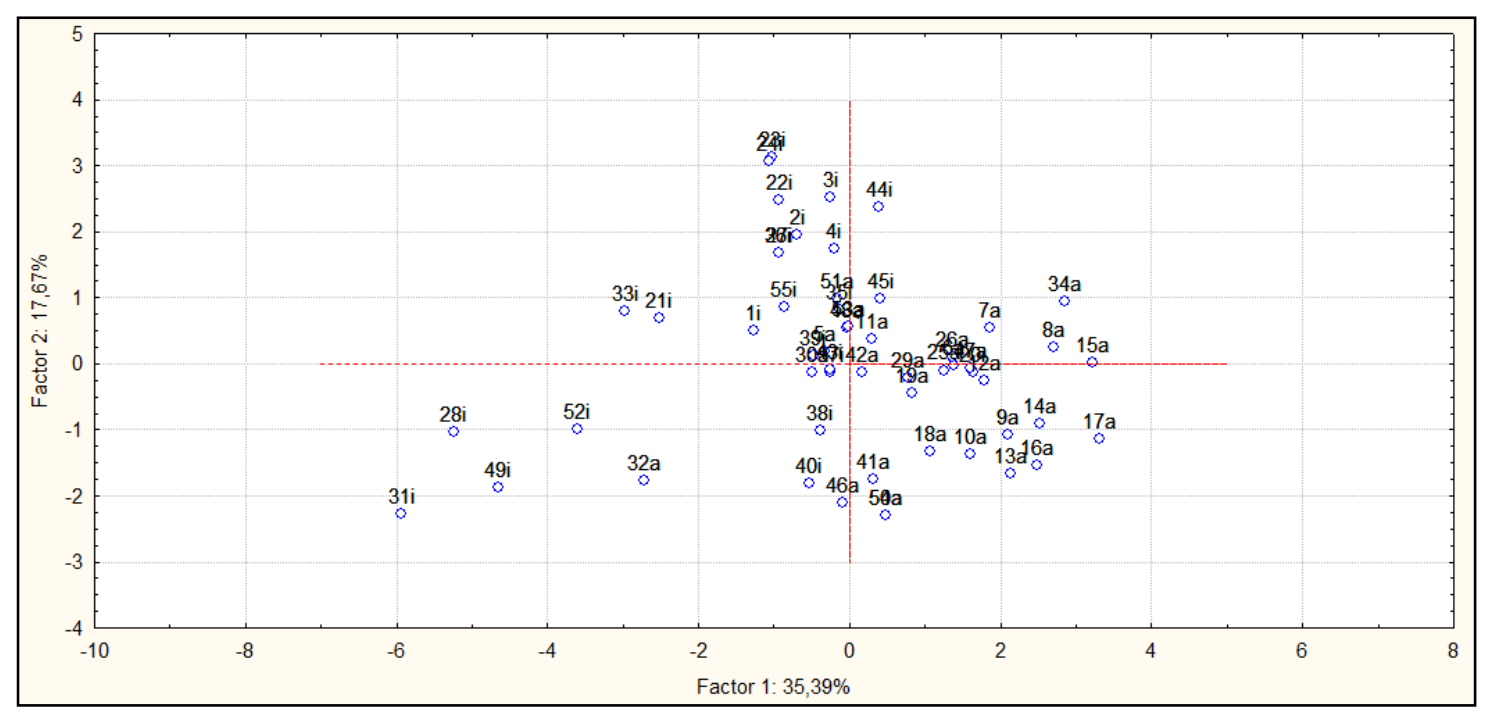

A

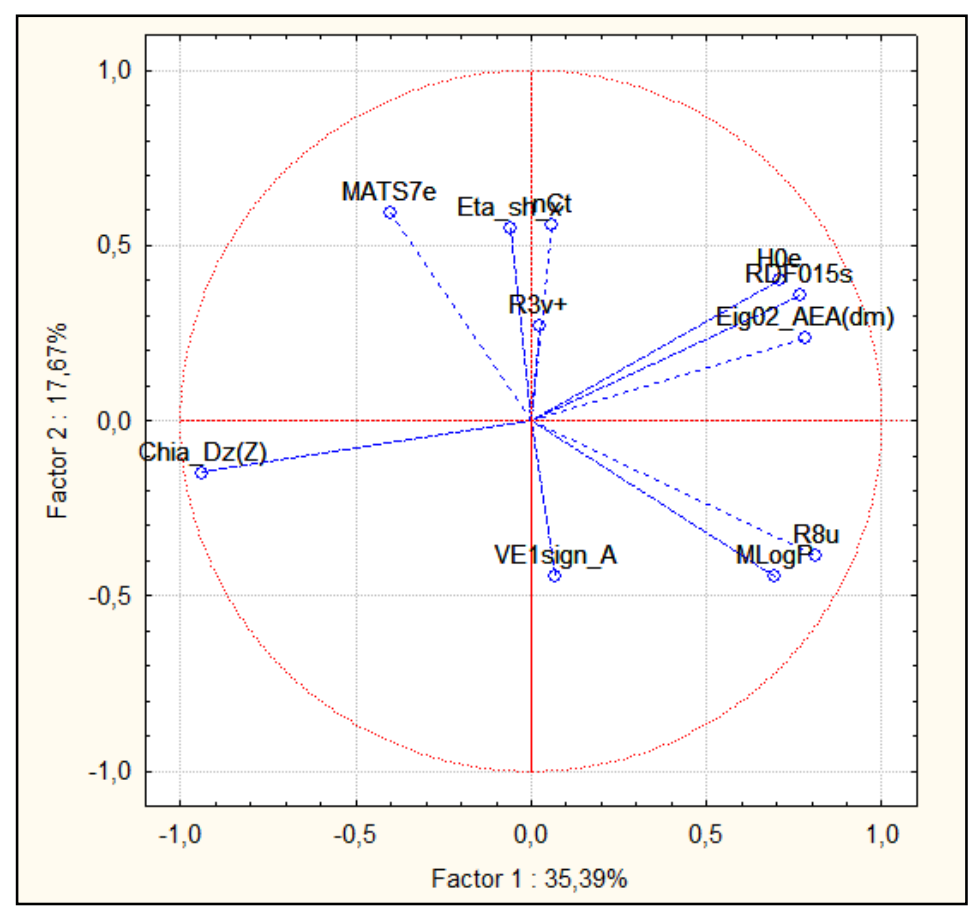

B

Figure 2. Initial exploratory PCA with a priori and algorithm selected descriptors (A - Plot of scores. B - Plot of loadings) 


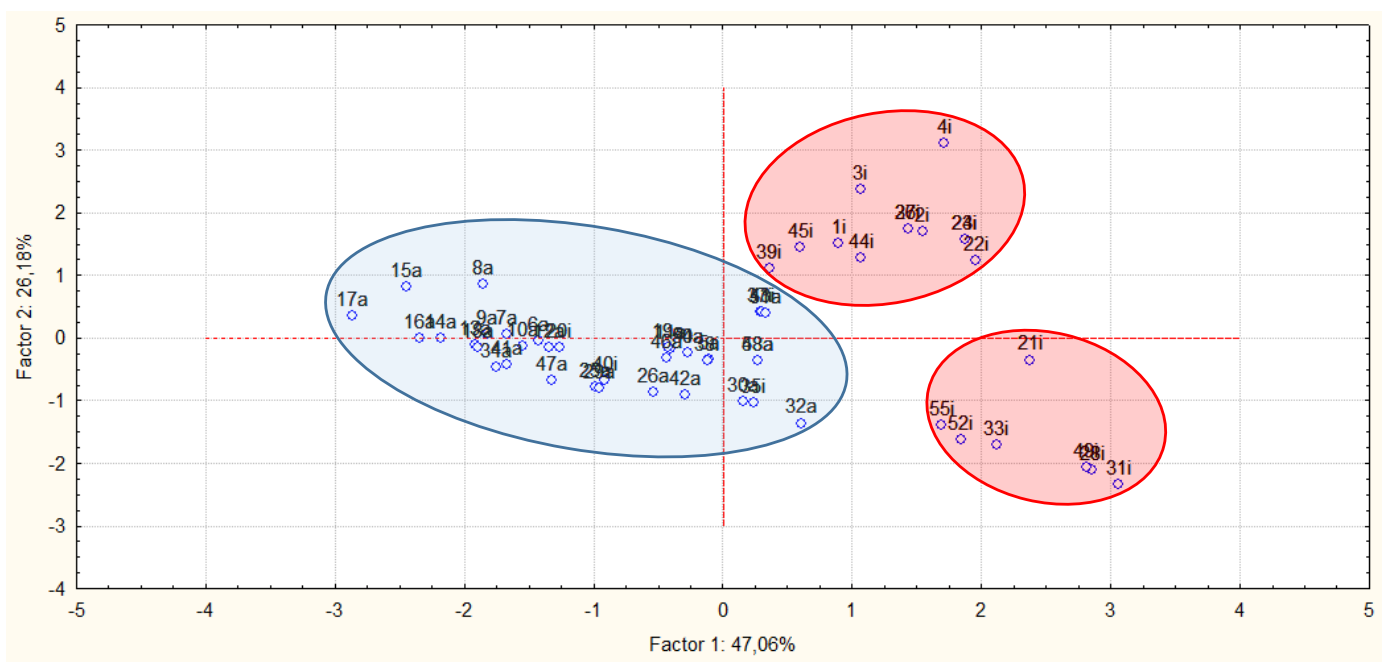

A

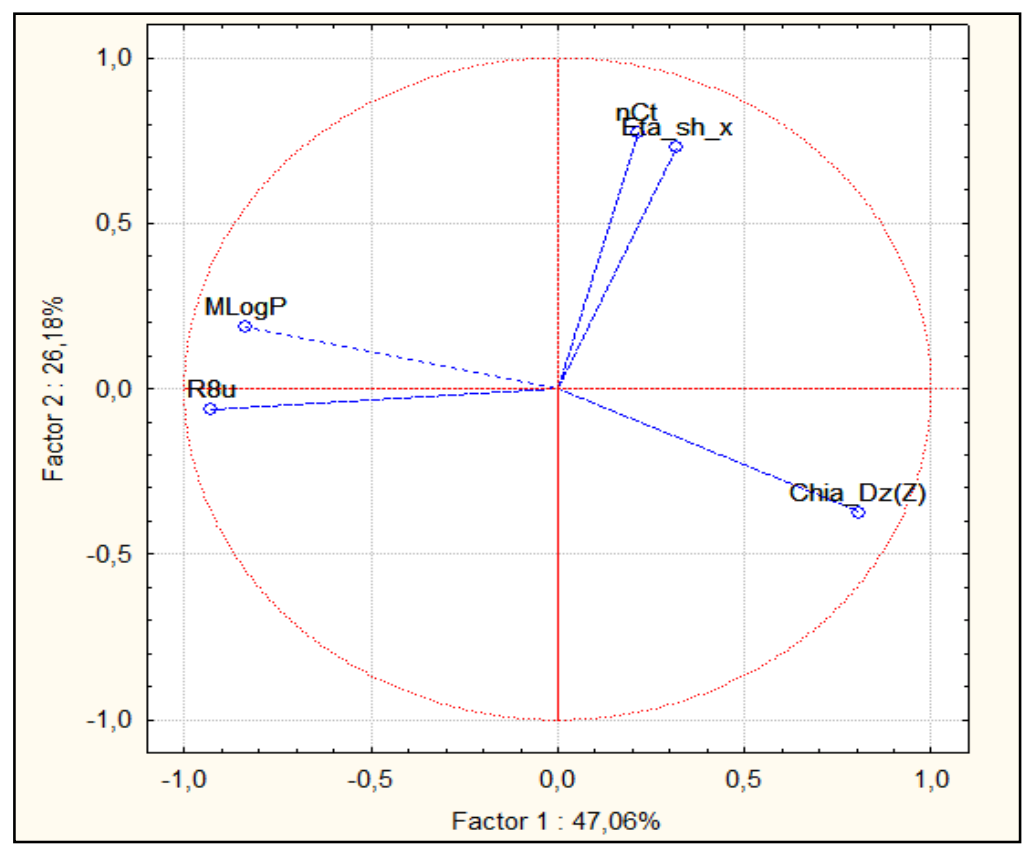

B

Figure 3. PCA with the best variables selected by loadings plot and clustering on scores

In addition to the classification model generated, the chemical sense of the descriptors is very important on the establishment of structure-activity relationships, aiming to understand the molecular reasons of the activity and proposition of new compounds, beyond of the intrinsic predictive power of the SIMCA plot.

MLogP is the Moriguchi-Log of the coefficient of partition on octanol/water system. It is a general measure of the lipophilicity of the compounds, where higher values lead to be more actives. ${ }^{11}$ In turn, $\mathrm{nCt}$ is a descriptor that considers the absolute number of tertiary carbons when more ramified molecules have higher values of the descriptor and tend to be less actives, while the $\mathrm{R} 8 \mathrm{u}$ is an autocorrelation descriptor, based on the lag of 8 atoms, without any correlation scheme. ${ }^{11}$ As higher their value, most elongated is the structure, what leads to 
an increment on activity. Then, compounds elongated and with a 1,4-substitution pattern on the ring, tend to be more actives. ${ }^{11}$

Table 2. Results of the classifications using the SIMCA model. (In blue, compounds wrongly classified. In red and green, the correct associations).

\begin{tabular}{|c|c|c|c|}
\hline Compound & Classified into the model & Compound & $\begin{array}{c}\text { Classified into the } \\
\text { model }\end{array}$ \\
\hline $1 \mathbf{i}$ & No & $29 a$ & Yes \\
\hline $2 \mathbf{i}$ & No & $30 a^{*}$ & Yes \\
\hline $3 \mathbf{i}$ & No & $31 \mathbf{i}$ & No \\
\hline $4 i$ & No & $32 a$ & Yes \\
\hline $5 a^{*}$ & Yes & $33 \mathbf{i}$ & No \\
\hline $6 a$ & Yes & $34 a$ & Yes \\
\hline $7 a$ & Yes & $35 i$ & No \\
\hline $8 a$ & Yes & $36 \mathbf{i}$ & No \\
\hline $9 a$ & Yes & $37 i$ & No \\
\hline $10 a$ & Yes & $38 \mathrm{i}$ & Yes \\
\hline $11 a$ & Yes & $39 i$ & No \\
\hline $12 a$ & Yes & $40 i$ & Yes \\
\hline $13 a$ & Yes & $41 a$ & Yes \\
\hline $14 a$ & Yes & $42 a^{*}$ & Yes \\
\hline $15 a$ & Yes & $43 i$ & No \\
\hline $16 a$ & Yes & $44 i$ & No \\
\hline $17 a$ & Yes & $45 i$ & No \\
\hline $18 a$ & Yes & $46 a$ & Yes \\
\hline $19 a$ & Yes & $47 a$ & Yes \\
\hline $20 \mathrm{i}$ & Yes & $48 a^{*}$ & Yes \\
\hline $21 i$ & No & $49 i$ & No \\
\hline $22 i$ & No & $50 a$ & Yes \\
\hline $23 i$ & No & $51 a^{*}$ & No \\
\hline $24 i$ & No & $52 i$ & No \\
\hline $25 a$ & Yes & $53 a^{*}$ & Yes \\
\hline $26 a^{*}$ & Yes & $54 a$ & Yes \\
\hline $27 i$ & No & $55 i$ & No \\
\hline $28 \mathrm{i}$ & No & & \\
\hline
\end{tabular}

*Test set 
ChiA_Dz(z) and Eta_sh_x are indexes firstly related here to the larvicidal activity of monoterpenes and analogs, selected by the CCV-based algorithm. The first corresponds to the "average Randic-like index from Barysz matrix weighted by atomic number". ${ }^{17}$ The Barysz Distance Matrix (Dz) is a weighted distance matrix accounting for the presence of heteroatoms and multiple bonds. In general, less active molecules have higher values of this descriptor, reinforcing the idea that more electronegative atoms (that in general has a higher atomic number, as oxygen) into the basic scaffold of the compounds ("heteroatoms"), tend to lose the active power. This is in accordance with other descriptors discussed by us. ${ }^{10}$

Finally, the Eta_sh_x descriptor is the "eta $x$ shape index", which is easily computed from the information of molecular composition and two-dimensional representations. ${ }^{18}$ The general aspect of "ETA" formalism is performed using the hydrogen suppressed molecular graph-based distance matrix. ${ }^{18}$ For this descriptor, higher values lead to less active compounds, corresponding to a dense and branched distribution of atoms. Compounds $1 \mathrm{i}-4 \mathrm{i}$ are representatives of this aspect.

\section{Conclusion}

The strategy to eliminate the Aedes aegypti with the use of different insecticide and larvicidals (organophosphates, pyrethroids and growth regulators) has resulted in the growing vector resistance and environmental toxicity. The CCV-based algorithm was able to select important molecular descriptors, aiming to generate a predictive classification model for monoterpenes and analog compounds with larvicidal activity in Aedes aegypti.

The steps related here represent a low cost and time method, can be applied and tested in other SIMCA procedures involving constitutional, topological and connectivity index, as Dragon molecular descriptors. For the presented specific data set, two important molecular descriptors were highlighted, together with three others a priori variables. Compounds with less ramified structures, less electronegative heteroatoms, more lipophilic and elongated scaffolds tend to be more actives, corroborating previous works of our research group. The main goal in this paper is that the classification model showed a good degree of predictability and can be used, allied to other models or chemoinformatic tools, for the search and test of structurally related compounds.

\section{Acknowledgments}

The authors thank to CNPq, CAPES, FACEPE and UNIVASF for the financial support and scholarships as well as the CENAPAD-UFC for the computational facilities. The activity of access to the genetic patrimony was registered in SisGen with code \#A079750.

\section{References}

${ }^{1}$ Vasconcelos, P. F.; Calisher, C. H.; Emergence of human arboviral diseases in the 425 Americas, 2000-2016. Vector Borne Zoonotic Diseases 2016, 16, 295. [CrossRef]

${ }^{2}$ Rückert, C.; Weger-Lucarelli, J.; Garcia-Luna, S. M.; Young, M. C.; Byas, A. D.; Murrieta, R. A.; Fauver, J. R.; Ebel, G. D. Impact of simultaneous exposure to arboviruses on infection and transmission by Aedes aegypti mosquitoes. Nature Communications 2017, 8 , 15412. [CrossRef]

${ }^{3}$ Wilder-Smith, A.; Gubler, D. J.; Weaver, S. C.; Monath, T. P.; Heymann, D. L.; Scott, T. W. Epidemic arboviral diseases: priorities for research and public health. The Lancet 2017, 3, e101. [CrossRef]

${ }^{4}$ Zara, A. L. S. A.; Santos, S. M.; FernandesOliveira, E. S.; Carvalho, R. G.; Coelho, G. E. Estratégias de controle do Aedes aegypti: uma revisão. Epidemiologia e Serviços de Saúde 2016, 25, 391. [CrossRef] 
${ }^{5}$ Augusto, L. G S.; Gurgel, A. M.; Costa, A. M.; Diderichsen, F.; Lacaz, F. A.; Parra-Henao, G.; Rigotto, R. M.; Nodari, R.; Santos, S. L. Aedes aegypti control in Brazil. The Lancet Infectious Diseases 2016, 387, 1052. [CrossRef]

${ }^{6}$ Silva, G. N. S.; Trindade, F. T. T.; Santos, F.; Gosmann, G.; Gnoatto, S. C. B. Larvicidal activity of natural and modified triterpenoids against Aedes aegypti (Diptera: Culicidae). Pest managment science 2016, 72, 1883. [CrossRef]

${ }^{7}$ Santos, S. R. L.; Silva, V. B.; Melo, M. A.; Barbosa, J. D. F.; Santos, R. L. C.; de Sousa, D. P.; Cavalcanti, S. C. H.; Toxic Effects on and Structure-Toxicity Relationships of Phenylpropanoids, Terpenes, and Related Compounds in Aedes aegypti Larvae. VectorBorne Zoonotic 2010, 10, 1049. [CrossRef]

${ }^{8}$ Santos, S. R. L.; Melo, M. A.; Cardoso, A. V.; Santos, R. L. C.; de Sousa, D. P.; Cavalcanti, S. C. H.; Structure-activity relationships of larvicidal monoterpenes and derivatives against Aedes aegypti Linn. Chemosphere 2011, 84, 150. [CrossRef]

${ }^{9}$ Scotti, L.; Tullius-Scotti, M.; Barros-Silva, V.; Lima-Santos, S. R.; Cavalcanti, S. C. H.; Mendonça Junior, F. J. B. Chemometric studies on potential larvicidal compounds against Aedes aegypti. Medicinal Chemistry 2014, 10 , 201. [CrossRef]

${ }^{10}$ Alencar Filho, E. B.; Castro Silva, J. W.; Cavalcanti, S. C. H. Quantitative structuretoxicity relationships and molecular highlights about Aedes aegypti larvicidal activity of monoterpenes and related compounds. Medicinal Chemistry Research 2016, 25, 2171. [CrossRef]

${ }^{11}$ Santos, I. M.; Carvalho, T. G.; Agra, J. P. G.; Maia, G. L. A.; Alencar Filho, E. B. Classical and 3D QSAR studies of larvicidal monoterpenes against Aedes aegypti: New molecular insights for the rational design of more active compounds. Structural Chemistry 2018, 29, 1287. [CrossRef]
${ }^{12} \mathrm{ACD} /$ ChemSketch, version 12.01, Advanced Chemistry Development, Inc., Toronto, ON, Canada, www.acdlabs.com, 2015.

${ }^{13}$ GaussView, Version 6, Dennington, Roy; Keith, Todd A.; Millam, John M. Semichem Inc., Shawnee Mission, KS, 2016.

${ }^{14}$ Gaussian 09W, Revision B.01, Frisch, M. J.; Trucks, G. W.; Schlegel, H. B.; Scuseria, G. E.; Robb, M. A.; Cheeseman, J. R.; Scalmani, G.; Barone, V.; Petersson, G. A.; Nakatsuji, H.; Li, X.; Caricato, M.; Marenich, A. V.; Bloino, J.; Janesko, B. G.; Gomperts, R.; Mennucci, B.; Hratchian, H. P.; Ortiz, J. V.; Izmaylov, A. F.; Sonnenberg, J. L.; Williams-Young, D.; Ding, F.; Lipparini, F.; Egidi, F.; Goings, J.; Peng, B.; Petrone, A.; Henderson, T.; Ranasinghe, D.; Zakrzewski, V. G.; Gao, J.; Rega, N.; Zheng, G.; Liang, W.; Hada, M.; Ehara, M.; Toyota, K.; Fukuda, R.; Hasegawa, J.; Ishida, M.; Nakajima, T.; Honda, Y.; Kitao, O.; Nakai, H.; Vreven, T.; Throssell, K.; Montgomery, J. A., Jr.; Peralta, J. E.; Ogliaro, F.; Bearpark, M. J.; Heyd, J. J.; Brothers, E. N.; Kudin, K. N.; Staroverov, V. N.; Keith, T. A.; Kobayashi, R.; Normand, J.; Raghavachari, K.; Rendell, A. P.; Burant, J. C.; lyengar, S. S.; Tomasi, J.; Cossi, M.; Millam, J. M.; Klene, M.; Adamo, C.; Cammi, R.; Ochterski, J. W.; Martin, R. L.; Morokuma, K.; Farkas, O.; Foresman, J. B.; Fox, D. J. Gaussian, Inc., Wallingford CT, 2016.

${ }^{15}$ Kode srl, Dragon (software for molecular descriptor calculation) version 7.0.10, 2017, 382. [Link].

${ }^{16}$ Fong, S.; Liang, J.; Wong, R.; Ghanavati, M. A novel feature selection by clustering coefficients of variations. $\mathrm{Nin}^{\text {th }}$ International Conference on Digital Information Management (ICDIM 2014) 2014, 205. [CrossRef]

${ }^{17}$ Sítio da Talete products. Disponível em: $<$ http://www.talete.mi.it/products/dragon molecular_descriptor_list.pdf $>$. Acesso em: 20 abril 2018.

${ }^{18}$ Roy, K.; Quantitative Structure-Activity Relationships in Drug Design, Predictive Toxicology, and Risk Assessment. IGI Global, Hershey PA USA, 2015. 